\title{
Nuclear Nox4-Derived Reactive Oxygen Species in Myelodysplastic Syndromes
}

\author{
Marianna Guida, ${ }^{1}$ Tullia Maraldi, ${ }^{1}$ Francesca Beretti, ${ }^{1}$ Matilde Y. Follo, ${ }^{2}$ \\ Lucia Manzoli, ${ }^{2}$ and Anto De Pol ${ }^{1}$ \\ ${ }^{1}$ Department of Surgical, Medical, Dental and Morphological Sciences with interest in Transplant, Oncology and \\ Regenerative Medicine, University of Modena and Reggio Emilia, Via Del Pozzo 71, 41124 Modena, Italy \\ ${ }^{2}$ Department of Human Anatomic Sciences, University of Bologna, Via Irnerio 48, 40100 Bologna, Italy
}

Correspondence should be addressed to Tullia Maraldi; tullia.maraldi@unimore.it

Received 15 November 2013; Accepted 21 January 2014; Published 26 February 2014

Academic Editor: Cristina Angeloni

Copyright ( 2014 Marianna Guida et al. This is an open access article distributed under the Creative Commons Attribution License, which permits unrestricted use, distribution, and reproduction in any medium, provided the original work is properly cited.

A role for intracellular ROS production has been recently implicated in the pathogenesis and progression of a wide variety of neoplasias. ROS sources, such as $\mathrm{NAD}(\mathrm{P}) \mathrm{H}$ oxidase (Nox) complexes, are frequently activated in AML (acute myeloid leukemia) blasts and strongly contribute to their proliferation, survival, and drug resistance. Myelodysplastic syndromes (MDS) comprise a heterogeneous group of disorders characterized by ineffective hematopoiesis, with an increased propensity to develop AML. The molecular basis for MDS progression is unknown, but a key element in MDS disease progression is the genomic instability. NADPH oxidases are now recognized to have specific subcellular localizations, this targeting to specific compartments for localized ROS production. Local Nox-dependent ROS production in the nucleus may contribute to the regulation of redox-dependent cell growth, differentiation, senescence, DNA damage, and apoptosis. We observed that Noxl, 2, and 4 isoforms and p22phox and Racl subunits are expressed in MDS/AML cell lines and MDS samples, also in the nuclear fractions. Interestingly, Nox4 interacts with ERK and Aktl within nuclear speckle domain, suggesting that Nox4 could be involved in regulating gene expression and splicing factor activity. These data contribute to the elucidation of the molecular mechanisms used by nuclear ROS to drive MDS evolution to AML

\section{Introduction}

The progression of a premalignant condition to a lethal malignancy is thought to involve an accumulation of mutations in genes that regulate cellular proliferation, survival, and differentiation $[1,2]$. The myelodysplastic syndromes (MDSs) can be considered as a representative premalignant hematopoietic disorder that can transform to acute myeloid leukemia (AML) [3].

(Da Watson) MDS comprises a group of anemic disorders of uncertain etiology characterized by abnormal cell morphology in the bone marrow (BM) and peripheral blood cytopenias [4]. According to the International Prognostic Scoring System, the patients with MDS can be divided into 4 prognostic categories: low, intermediate I, intermediate II, and high risk [5]. In about one-third of the patients with MDS, the disease transforms into AML, within months to a few years. These patients usually have a high risk disease, including Int II or high-risk MDS [6]. The causative agent(s) for these secondary events is poorly understood. The excess ROS are known to be a genotoxic stress that can induce DNA damage and mutation following ineffective repair of DNA damage [7-10]. Increased levels of ROS have been detected in both AML and chronic myeloid leukemia [11,12]. With regard to MDS and oxidative stress, several studies have reported that increased levels of ROS or oxidative DNA damage could be detected in hematopoietic cells from MDS patients [13-15].

It has been demonstrated that RAS mutations in myelodysplastic syndromes/myeloproliferative diseases result in ROS production [16]. Moreover, another player of inositide 
signaling; that is, phosphatidylinositol 3 kinase (PI3K) has been suggested to be involved, via its substrate Akt, in the survival of MDS blasts [17].

$\mathrm{NAD}(\mathrm{P}) \mathrm{H}$ oxidase complexes, as ROS sources, are frequently activated in AML blasts and strongly contribute to proliferation, survival, and drug resistance of these cells [18-20]. In leukemia cells, ROS generated by Nox4, at least in part, transmit survival signals through the AktPI3K pathway while their depletion leads to apoptosis [21]. Furthermore, NADPH oxidases are now recognized to have specific subcellular localizations, thus being required for localized ROS production [22]. Various ROS-generating and ROS-degrading systems seem to play an important role in different compartments of the cell. The nucleus itself contains a number of proteins with oxidizable thiols that are essential for transcription, chromatin stability, nuclear protein import and export, and DNA replication and repair [23].

Kuroda et al. demonstrated that the endogenous Nox4 preferentially localizes to the nucleus in human endothelial cells [24]. Thus, local Nox4-dependent ROS production in the nucleus may contribute to regulation of redox-dependent transcription factor and gene expression involved in cell growth, differentiation, senescence, and apoptosis. In fact, many transcription factors, including AP-1, NF- $\kappa \mathrm{B}, \mathrm{Nrf} 2$, p 53 , glucocorticoid receptor, and nuclear kinases, such as $\mathrm{PKC}$ (Protein kinase C), Akt, ERK2, and PKA (Protein kinase A), are redox sensitive $[22,25]$.

In spite of these striking observations, most ROS nuclear substrates have so far remained elusive, as well as nuclear Nox4-derived ROS functions. Therefore, the first aim of this study is to determine if Nox4 isoform is present in the nucleus of MDS cells and the specific localization area of Nox4 complex. We therefore used the human cell line MOLM13, established from AML secondary to myelodysplastic syndrome and the AML cell line THP1 and/or human blasts obtained from patients with MDS. The broad object of this research is to elucidate the role of nuclear Nox-derived ROS in myelodysplastic syndromes. Therefore, Nox4 expression has been down-regulated and ROS decrease in the nucleus has been checked in order to confirm the nuclear localization and activity of NADPH oxidase.

Then, we searched for binding partners in the nucleus, in particular signaling key molecules. To reveal the interactome proteins that reside in nuclear Nox complex in human MDS/AML cell line, coimmunoprecipitation assay has been performed in order to check Nox interactions with nuclear signaling players. Identification of substrates or binding partners of nuclear $\mathrm{NAD}(\mathrm{P}) \mathrm{H}$ oxidases will pave the way to finding new pharmacological treatments.

The data resulting from the present study could contribute to shedding the light on the molecular mechanisms used by this key intracellular pathway to drive MDS evolution to AML and, in general, in hematological dysfunctions.

\section{Materials and Methods}

2.1. Patient Characteristics. Peripheral blood samples (PBMCs) came from $10 \mathrm{MDS}$ patients and 3 healthy normal volunteers who had given informed consent according to the Declaration of Helsinki. The samples came from the Department of Hematology and Medical Oncology (L. e A. Seràgnoli) of the Policlinico S. Orsola, Bologna, Italy. In all of the subjects participating in this study, MDS diagnosis was defined according to WHO classification [26]. For in vitro experiments, PBMCs were isolated by Ficoll-Paque (Amersham Biosciences, Sunnyvale, CA, USA) densitygradient centrifugation, according to the manufacturer's protocol.

2.2. Cell Culture. The MDS cell line MOLM13 and the AML cell line THP1 were purchased from DSMZ (German Resource Centre for Biological Material). MOLM-13 cells express FLT3-ITD and have been derived from the peripheral blood of a patient with post-MDS AML [27, 28]. MOLM-13 carries internal tandem duplication of FLT3. THP1 is an acute monocytic leukemia cell line.

Cell lines were cultured with $5 \% \mathrm{CO}_{2}$ at $37^{\circ} \mathrm{C}$ in RPMI (Mediatech, Inc., Herndon, VA) with $10 \%$ fetal calf serum (FCS) and supplemented with $2 \mathrm{mM} \mathrm{L}$-glutamine, $100 \mathrm{U} / \mathrm{mL}$ penicillin, and $100 \mu \mathrm{g} / \mathrm{mL}$ streptomycin (all from EuroClone Spa, Italy).

2.3. Nox4 Silencing. Retroviral supernatants were produced according to HuSH shRNA Plasmid Panels (29-mer) Application Guide; AM12 cells were transfected with an empty vector (pRS Vector, TR20003), a scrambled vector (HuSH 29-mer non effective pRS vector, TR30012), and four NOX4 gene specific shRNA expression pRS vectors (TI311637, TI311638, TI311639, and TI311640) for $48 \mathrm{~h}$. Retroviral supernatants were then centrifuged at $2000 \times \mathrm{g}$ for 5 minutes and used for target cells (THP1) infection. Where indicated, cells were infected with NOX4 shRNA retroviral vectors, empty vector, or scrambled vector. Forty-eight hours after infection, cells were exposed to $2 \mu \mathrm{g} / \mathrm{mL}$ puromycin (Sigma Aldrich) for 24 hours, and subjected to evaluation of Nox4 expression by Western blotting and confocal analysis and detection of intracellular ROS levels.

2.4. Preparation of Cell Extracts. Cell extracts were obtained as described by Maraldi et al. [29]. Briefly, cells were extracted by addition of AT lysis buffer $(20 \mathrm{mM}$ Tris- $\mathrm{Cl}, \mathrm{pH}$ 7.0; 1\% Nonidet P-40; $150 \mathrm{mM} \mathrm{NaCl} ; 10 \%$ glycerol; $10 \mathrm{mM}$ EDTA; $20 \mathrm{mM}$ NaF; $5 \mathrm{mM}$ sodium pyrophosphate; and $1 \mathrm{mM}$ $\mathrm{Na} 3 \mathrm{VO} 4)$ and freshly added Sigma Aldrich Protease Inhibitor Cocktail at $4^{\circ} \mathrm{C}$ for $30 \mathrm{~min}$. Lysates were sonicated, cleared by centrifugation, and immediately boiled in SDS sample buffer or used for immunoprecipitation experiments, as described below.

2.5. Nuclei Purification. Cell nuclei were purified as reported by Cenni et al. [30]. Briefly, $400 \mu \mathrm{L}$ of nuclear isolation buffer $(10 \mathrm{mM}$ Tris-HCl, pH 7.8, 1\% Nonidet P-40, $10 \mathrm{mM}$ $\beta$-mercaptoethanol, $0.5 \mathrm{mM}$ phenylmethylsulfonyl fluoride, $1 \mu \mathrm{g} / \mathrm{mL}$ aprotinin and leupeptin, and $5 \mathrm{mM} \mathrm{NaF}$ ) was added to $5 \times 10^{6}$ cells for $8 \mathrm{~min}$ on ice. MilliQ water $(400 \mu \mathrm{L})$ was then added to swell cells for $3 \mathrm{~min}$. Cells were sheared by 
passages through a 22-gauge needle. Nuclei were recovered by centrifugation at $400 \times \mathrm{g}$ at $4^{\circ} \mathrm{C}$ for $6 \mathrm{~min}$ and washed once in $400 \mu \mathrm{L}$ of washing buffer (10 mM Tris- $\mathrm{HCl}, \mathrm{pH} 7.4$, and $2 \mathrm{mM} \mathrm{MgCl}_{2}$, plus inhibitors as described earlier in the text). Supernatants (containing the cytosolic fractions) were further centrifuged for $30 \mathrm{~min}$ at $4000 \times \mathrm{g}$. Isolated nuclear and cytoplasmic extracts were finally lysed in AT lysis buffer, sonicated, and cleared by centrifugation.

2.6. Immunoprecipitation and Electrophoresis. Immunoprecipitation was performed as reported by Bertacchini et al. [31]. For preclearing procedure nuclear lysates were incubated with $2 \mu \mathrm{g}$ anti-M2 for 1 hour (Sigma Aldrich) and then with beads for additionally $30 \mathrm{~min}$, which were then removed and discarded prior to the immunoprecipitation. Precleared lysates, whose protein concentration was determined by the Bradford method, were incubated 4 hours with $3 \mu \mathrm{g}$ of antiNox4 (Novus Biologicals, CO, USA). Then samples were treated with $30 \mu \mathrm{L}$ of $50 \%(\mathrm{v} / \mathrm{v})$ of protein $\mathrm{A} / \mathrm{G}$ agarose slurry (GE Healthcare Biosciences, Uppsala, Sweden) at $4^{\circ} \mathrm{C}$ with gentle rocking for $1 \mathrm{~h}$. Pellets were washed twice with $20 \mathrm{mM}$ Tris-Cl, pH 7.0; $1 \%$ Nonidet P-40; 150 mM NaCl; $10 \%$ glycerol; $10 \mathrm{mM}$ EDTA; $20 \mathrm{mM} \mathrm{NaF}$; $5 \mathrm{mM}$ sodium pyrophosphate, once with $10 \mathrm{mM}$ Tris- $\mathrm{Cl}, \mathrm{pH} 7.4$, boiled in SDS sample buffer, and centrifuged. Supernatants were loaded onto SDSpolyacrylamide gel, blotted on Immobilon-P membranes (Millipore, Waltham, MA, USA), and processed by Western blot with the indicated antibodies.

2.7. Western Blot. The protocols of the Western blot were performed as described by Hanson et al. [32]. Briefly, protein extracts, quantified by a Bradford Protein Assay (Bio-Rad Laboratories, CA, USA), underwent SDS-polyacrylamide gel electrophoresis and were transferred to Immobilon-P membranes. The following antibodies were used: rabbit antiERK1/2, goat anti-Matrin3, goat anti- $\beta$ actin, anti-p22phox (Santa Cruz Biotechnology, Santa Cruz, CA, USA) diluted 1:500, rabbit anti-Akt1, rabbit anti-Racl, and rabbit antiERK1/2 (Cell Signalling Technology, Beverly, MA, USA), mouse anti-tubulin, rabbit anti-Noxl, and mouse anti-sc35 (Sigma Aldrich St. Louis, MO, USA), rabbit anti-Nox4 (Novus Biologicals, CO, USA), rabbit anti-Nox2, and mouse anti-pH2A(Ser139) (Millipore, Billerica, MA, USA) diluted 1:1000; peroxidase-labelled anti-rabbit, mouse and goat secondary antibodies diluted 1:3000 (Pierce Antibodies, Thermo Scientific; Rockford, IL, USA). Ab dilution was performed in TBS-T pH 7.6 containing 3\% BSA. The membranes were visualized using Supersignal substrate chemiluminescence detection kit (Pierce, Rockford, IL, USA). Anti- $\beta$ actin antibody was used as control of protein loading. Quantization of the signal was obtained by chemiluminescence detection on a Kodak Image Station $440 \mathrm{CF}$ and analysis with the Kodak 1D Image software.

2.8. Confocal Microscopy. Cells were fixed for $20 \mathrm{~min}$ in $4 \%$ ice-cold paraformaldehyde and then permeabilized with $0.1 \%$ Triton X-100 in ice-cold phosphate-buffered saline (PBS) for 5 min. Permeabilized samples were then blocked with $3 \%$ of bovine serum albumin (BSA) in PBS for $30 \mathrm{~min}$ at room temperature and incubated with primary antibodies (Abs): rabbit anti-Nox4 (Santa Cruz, CA, USA) (diluted 1:50), mouse anti-sc-35 (Sigma Aldrich St. Louis, MO, USA) and mouse anti pH2A (Ser139) (Millipore, Billerica, MA, USA) (diluted 1:100), in PBS containing 3\% BSA for $1 \mathrm{~h}$ at RT. Secondary antibody was diluted 1:200 in PBS containing 3\% BSA (goat anti-mouse Alexa 647 and goat anti-rabbit Alexa 488). After washing in PBS, samples were stained with $1 \mu \mathrm{g} / \mathrm{mL}$ DAPI in $\mathrm{H}_{2} \mathrm{O}$ for $1 \mathrm{~min}$ and then mounted with antifading medium (0.21 M DABCO and $90 \%$ glycerol in $0.02 \mathrm{M}$ Tris, pH 8.0). Negative controls consisted of samples not incubated with the primary antibody, but only with the secondary antibody.

Confocal imaging was performed on a Nikon A1 confocal laser scanning microscope as previously described [33].

Spectral analysis was carried out to exclude overlapping between two signals or the influence of autofluorescence background on the fluorochrome signals, as previously shown [34]. The confocal serial sections were processed with Image J software to obtain three-dimensional projections, as previously described [35]. The image rendering was performed by Adobe Photoshop software.

2.9. Nuclear ROS Imaging. Nuclear ROS were detected with nuclear-localized fluorescent probe for $\mathrm{H}_{2} \mathrm{O}_{2}$, Nuclear Peroxy Emerald 1 (NucPE1) [36-39]. For all experiments, $5 \mu \mathrm{M}$ solutions of NucPE1 (from $5 \mathrm{mM}$ stocks in DMSO) were made in $\mathrm{PBS} /$ glucose. The cells were then kept in an incubator $\left(37^{\circ} \mathrm{C}\right.$, $5 \% \mathrm{CO}_{2}$ ) for a total of $30 \mathrm{~min}$ in the dark. Fluorescence was measured on a multiwell plate reader (Appliskan, Thermo Scientific) using $488 \mathrm{~nm}$ filter for excitation and $535 \mathrm{~nm}$ filter for emission.

Confocal fluorescence imaging studies were performed with a Nikon Al confocal laser scanning microscope. Excitation of NucPE1-loaded cells at $488 \mathrm{~nm}$ was carried out with an Ar laser and emission was collected at $535 \mathrm{~nm}$. All images in an experiment were collected simultaneously using identical microscope settings. Image analysis was performed in Image J.

2.10. Statistical Analysis. In vitro experiments were performed in triplicate. For quantitative comparisons, values were reported as mean \pm SD based on triplicate analysis for each sample. To test the significance of observed differences between the study groups, unpaired Student's $t$-test was applied. A $P$ value $<0.05$ was considered to be statistically significant.

\section{Results}

3.1. Patient Characteristics. Peripheral blood (PB) MCs from 10 patients affected by MDS ( 5 treated with azacitidine, 2 with hydroxyurea, 1 with erythropoietin and 2 with best supportive care only) were examined. Median age was 70 years (range 65 to 82 years). MDS was diagnosed following World Health Organization (WHO) classification [26]. Patient demographics and disease characteristics are summarized in Table 1. 
TABLE 1: Clinical, hematologic, and cytogenetic characteristics of MDS patients.

\begin{tabular}{lccc}
\hline $\begin{array}{l}\text { WHO } \\
\text { diagnosis }\end{array}$ & Karyotype & Treatment & Clinical outcome \\
\hline RARS & Normal & & $\begin{array}{c}\text { Stable disease } \\
\text { Disease } \\
\text { progression, death }\end{array}$ \\
RCMD & del (7q) & & AML \\
RCMD & del (20q) & EPO & RAEB2 \\
RAEB1 & Normal & 5-aza & Stable disease \\
RAEB1 & del (5q) & Idrossiurea (HU) & Stable disease \\
RAEB1 & del (7q) & Idrossiurea (HU) & AML, death \\
RAEB2 & Tris (8) & 5-aza & AML, death \\
RAEB2 & Tris (8) & 5-aza & AML, death \\
RAEB2 & Normal & 5-aza & AML, death \\
AML & Normal & 5-aza &
\end{tabular}

Karyotype analysis shows that different abnormalities are present in the study group as well as different disease gravity levels, as shown by WHO classification.

3.2. NADPH Oxidases Expression in MDS Samples and MDS/AML Cell Lines. At first, we tested the expression level of NADPH oxidase isoforms and their subunits by Western blot (WB) analysis of total lysates of all the MDS collected samples and of human MDS/AML cell lines (THP1 and MOLM-13).

By using different kinds of affinity-purified antibodies raised against distinct immunogens from human Nox1, Nox2, Nox4, p22phox, and Racl, we demonstrated that all these proteins are present in MDS samples and human MDS/AML cell lines. Figure 1 shows the expression pattern of three representative MDS samples compared to MOLM-13 and THP1 cell lines and PBMC healthy donor. Nox1 and Nox4 isoforms seem to be highly expressed in all samples.

Interestingly, Nox4 is both expressed into the nucleus and in the cytoplasm. In fact, confocal analysis (Figure 2(a)) demonstrated that in different MDS samples (images representative of RAEB1, RAEB2, and RARS are shown) a punctate staining of Nox4 is detectable inside the nuclei. Noxl and Nox2 signals show a cytoplasmic localization (not shown). The same pattern has been observed also in MDS/AML cell lines (Figure 2(b)).

In order to demonstrate the specificity of the immunofluorescence signal, we performed Western blot analysis of nuclear and cytoplasm subfractions (Figure 3). Also with this approach we can see a high presence of Nox4 in nuclear portions; moreover, the Nox4 subunit p22phox is present in both the subfractions.

Rac, an important downstream effector of RAS, is an activator of Nox 2 and Nox 4 and, in leukemic cells, Rac-1 and Akt activate Nox2 and Nox4 [20, 40]. RAS/Nox have been also demonstrated to be modulators of cell growth and proliferation via activating the mitogen-activated protein kinase ERK1/2 signaling pathway [41]. Beside Nox4 and its regulators p22phox and Rac-1, here we show that Akt1 and

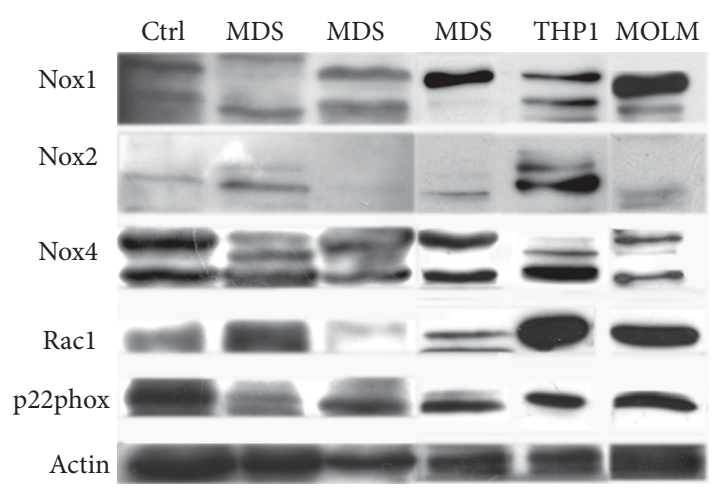

FIgURE 1: Expression of NADPH oxidases and their subunits. Representative images of Western blot analysis of total lysates of PBMC healthy donor (ctrl), MDS, MOLM-13, and THP1 samples revealed with antibodies against NADPH oxidase isoforms 1,2 , and 4 , Racl, and p22phox subunits. $\beta$ actin was used as loading internal control.

ERK1/2 are also present in nuclear protein portions of both MOLM-13 and THP1 cell lines (Figure 3).

3.3. Modulation of Nox-Derived Nuclear ROS Production. In order to investigate the NADPH oxidase activity inside the nuclei, we used a nuclear selective probe for $\mathrm{H}_{2} \mathrm{O}_{2}$, Nuclear peroxy Emerald 1 (Figure 4). Confocal microscopy confirms that there is a ROS production inside the nuclei (Figure 4(a)).

Even if the use of Nox4 synthetic inhibitor, diphenyleneiodonium (DPI), is not directed to the nuclear part of Nox4, as demonstrated by the fluorogenic probe assay, the Nox 4 activity inhibition reduces the nuclear ROS production (Figures 4(a) and 4(b)).

A more selective approach, as Nox4 silencing, confirms the Nox4 role in nuclear ROS production. The highest downregulation of Nox 4 was obtained with shRNA TI311638 and TI311640, as demonstrated by Western blot (Figure 4(d)). Immunofluorescence assay (Figure 4(c)) shows that the decrease in Nox 4 expression occurs both in cytoplasmic and nuclear compartments. Overall, THP1 cells, treated with all shRNA sequences, show a significant decrease in nuclear ROS level.

3.4. Nuclear Nox4 Role. The production of ROS directly inside the nuclei can be linked to DNA damage. In fact, increasing evidence suggests that genetic changes in myeloid malignancies lead to increased production of endogenous sources of DNA damage, such as reactive oxygen species.

It has been shown recently that the phosphorylation level of $\mathrm{H} 2 \mathrm{AX}$ is crucial to determining whether cells will survive after DNA damage [42].

Looking at nuclear H2A foci, as expected, we found that, compared to healthy donor, MDS samples exhibit a huge status of $\mathrm{H} 2 \mathrm{~A}$ phosphorylation (Figure 5), suggesting that nNox4-generated ROS can induce nuclear DNA damage.

Then, we investigated the nuclear Nox4 binding network (Figure 6). Based on the punctate Nox4 signal previously observed (Figure 2), we tested whether this distribution 
Human MDS samples
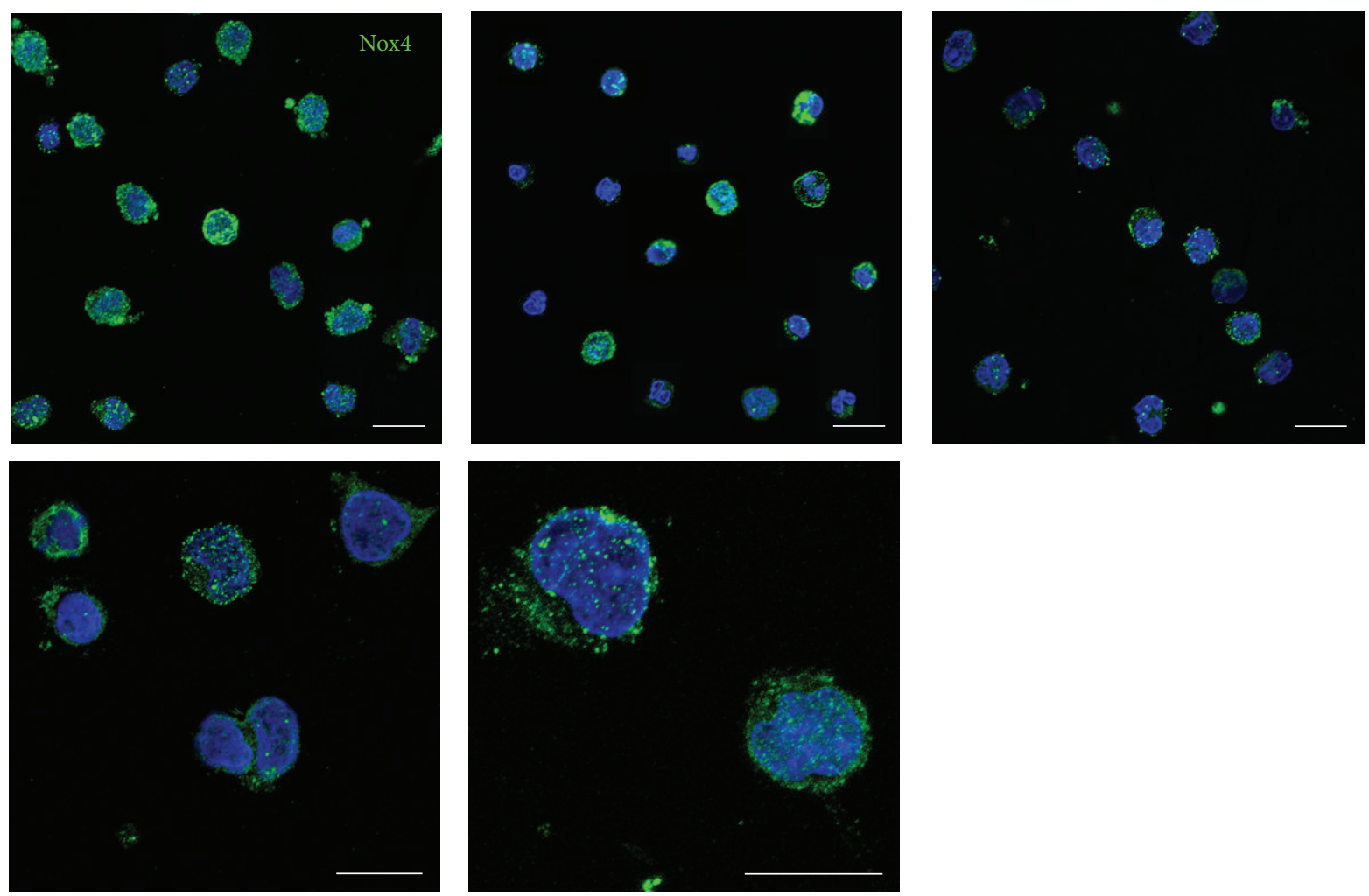

(a)
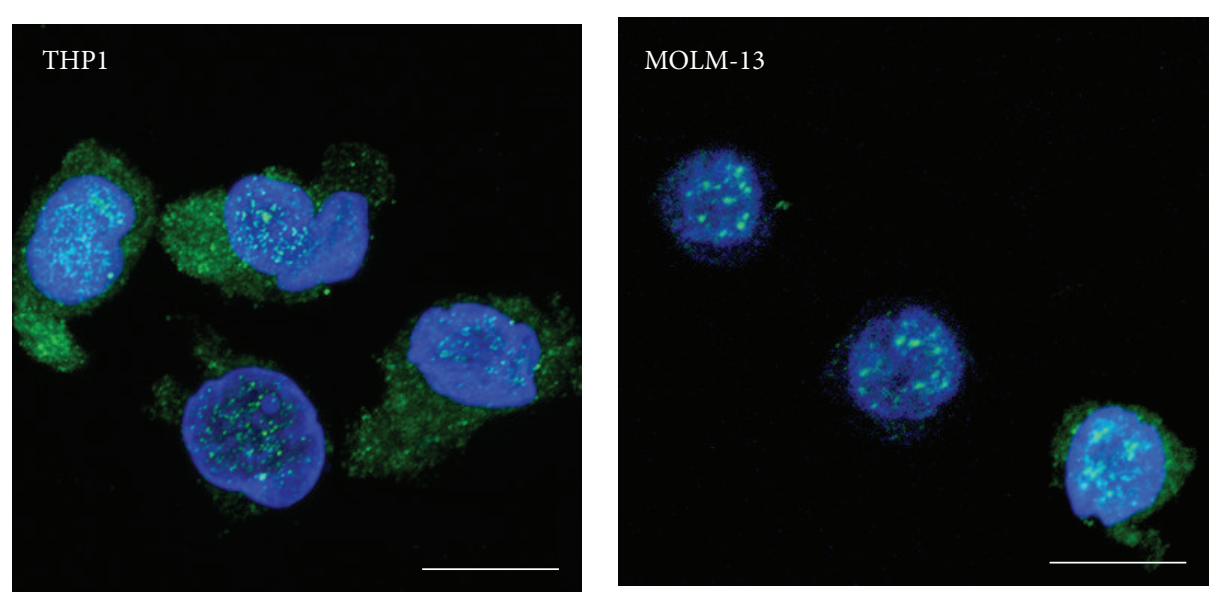

(b)

FIGURE 2: Immunofluorescence analysis of Nox4 expression. (a) Representative images at different magnifications showing superimposing between DAPI (blue) and Nox4 (green) signals in three human MDS samples (from left to right RAEB1, RAEB2, and RARS first row and RAEB1 and RAEB2 in the second row). (b) Representative images showing superimposing between DAPI (blue) and Nox4 (green) signals in MOLM-13 and THP1 samples. Scale bar: $10 \mu \mathrm{m}$.

follows the localization of speckles nuclear domains by using an antibody directed against sc-35. Sc-35 is involved in premRNA splicing and is found in the bodies in the nucleus referred to as speckles, sc-35 domains, or splicing factor compartments (SFCs). Figure 6(a) shows that the nuclear signal of Nox4 (green) often colocalizes with the one of sc35 (red), generating an orange staining. The arrow indicates, as example, the colocalization in MDS sample.
The interaction of Nox 4 with sc-35 was confirmed also by coimmunoprecipitation experiment (Figure 6(b)). Nuclear extracts (NL) of THP1 were used for coimmunoprecipitation analysis with anti-Nox4 (IPNox4), since this cell line express the highest level of nuclear Nox4. Preclearing fraction, obtained as described in method section, is shown as control for nonspecific interactions with protein $\mathrm{A} / \mathrm{G}$ : the only one band is the one of IgG used in the preclearing step. This 


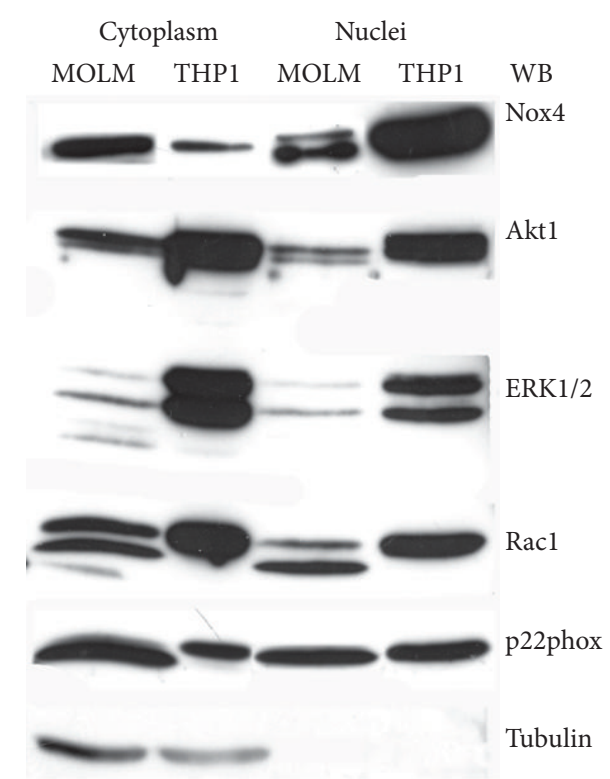

Figure 3: Western blot analysis of cytosol (cyto) and nuclear fractions (nuclei) of MOLM-13 and THP1 samples revealed with anti-Nox4, anti-Akt1, anti-ERK1/2, anti-Racl, and anti-p22phox. Tubulin absence was used as index of nuclear extract's purification. Presented data are representative of three independent experiments.

experiment also confirms the interaction between Nox4 and the subunit p22phox. Furthermore, Nox4 seems to be linked with nuclear matrix protein, Matrin3, and with ERK1/2 and Aktl, suggesting a direct role in nuclear MAPK and Akt signaling regulation.

\section{Discussion}

Myelodysplastic syndromes refer to a heterogeneous group of closely related hematological disorders that are characterized by an ineffective production of blood cells (dysplasia) and a hypercellular or hypocellular marrow with impaired morphology and maturation (dysmyelopoiesis) [5]. Although the genetic basis of MDS is not completely understood, a significant percentage of MDS cases are characterized by chromosomal aberrations $[43,44]$ and the transformation of MDS to AML is often accompanied by additional mutations [45]. Approximately, 30\% myelodysplastic syndrome (MDS) cases progress to acute myelogenous leukemia.

It is now well established that the progression of normal cells to neoplastic transformation results from the accumulation of mutations in genes that control cellular proliferation, survival, and differentiation [1].

It has been proposed that AML requires a minimum of two complementary mutations, one leading to enhanced proliferation and the second leading to impaired differentiation [46].

A significant percentage of MDS cases is characterized by chromosomal deletions of $5 \mathrm{q}$ or $7 \mathrm{q}$ [3] and has previously been reported to be high in a proportion of myeloid malignancies $[47,48]$. The next most frequent genetic alteration in
MDS is activating mutations of the RAS homologues occurring in $20 \%$ of MDS patients reviewed in $[49,50]$. Tumor progression is accompanied by an increase in ROS, which leads to an increased DNA damage. It is well established that activation of oncogenes can lead to ROS production [51], and ROS is an established source of endogenous doublestrand breaks [52]. Thus, acquisition of oncogenic changes can initiate a cycle of genomic instability that has the potential to create further mutations, which in turn may facilitate leukemic disease progression. Several lines of evidence now indicate that activation of RAS-mitogen-activated protein (MAP) kinase pathways can generate increased ROS. In fact, one candidate pathway for ROS production in MDS may be signaling through RAC1 [53]. Another candidate pathway for ROS production is signaling through extracellular signalregulated kinase 1/2 (ERK1/2).

It has been previously demonstrated that ERK phosphorylation occurred downstream from the Nox4 pathway, but through the RAS activation in endoplasmic reticulum [54]. The presence and the activity in the nucleus of both PI3K/Akt [55] and $\mathrm{NAD}(\mathrm{P}) \mathrm{H}$ oxidase isoform 4 have been described [24]. Indeed, the altered expression of Nox 4 could be involved in a dysregulation of cell cycle and has also an important meaning in high risk MDS patients. ROS can inactivate nuclear-localized phosphatases and thereby enhance kinase activation. Moreover, excessive production of ROS also could lead to oxidative DNA damage.

In this point of view, the subcellular localization of Nox 4 is likely to be especially important, given its constitutive activity, unlike isoforms, such as Noxl or Nox2, that require agonist activation.

We observed in human MDS samples, showing DNA damage sign and obtained from different disease grade patients, that Nox 4 isoform is, interestingly, localized into the nucleus. Inhibition of Nox4 activity, obtained with DPI or Nox4 silencing, induces a decline of nuclear ROS production, confirming the activity of Nox4 within the nuclei.

Confocal and coimmunoprecipitation analysis demonstrate Nox4 presences in speckle domains suggesting that Nox4 could be involved in regulating DNA-mRNA processing machinery by ROS production in specific nuclear area. Also Matrin 3 has been demonstrated to bind DNA at sites termed scaffold/matrix attachment regions to regulate gene expression through interactions with chromatin remodeling [56]. Here, we show that Nox4 coimmunoprecipitates also with Matrin 3. Thus, Matrin 3 could be a docking site where nuclear ROS signaling may exert its function on transcription/pre-mRNA modulation in specific nuclear domains.

Moreover, immunoprecipitation analysis demonstrated that Nox4 interacts with Akt and ERK signaling, suggesting a role in nuclear signaling dysregulation leading to MDS progression. The identification of these binding partners of nuclear Nox4 may pave the way to finding new pharmacological treatments.

Taken together, we suggest that nNox4 regulation may have important pathophysiologic effects in MDS through 


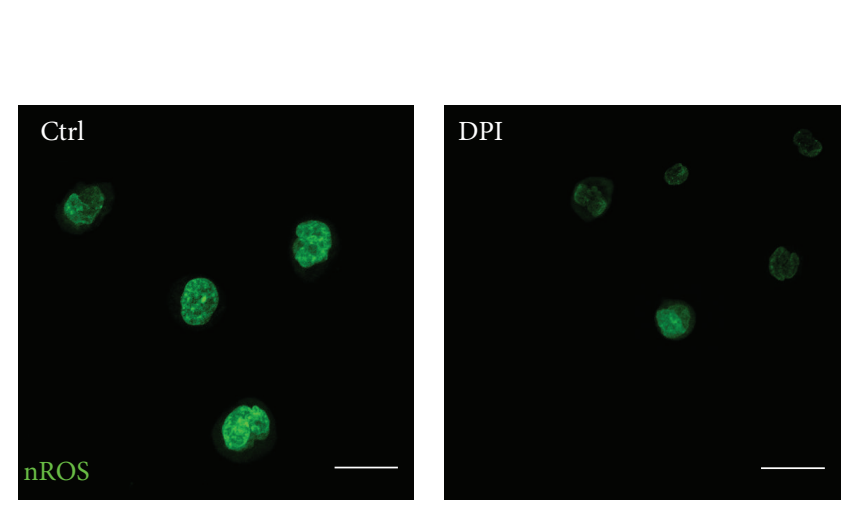

(a)
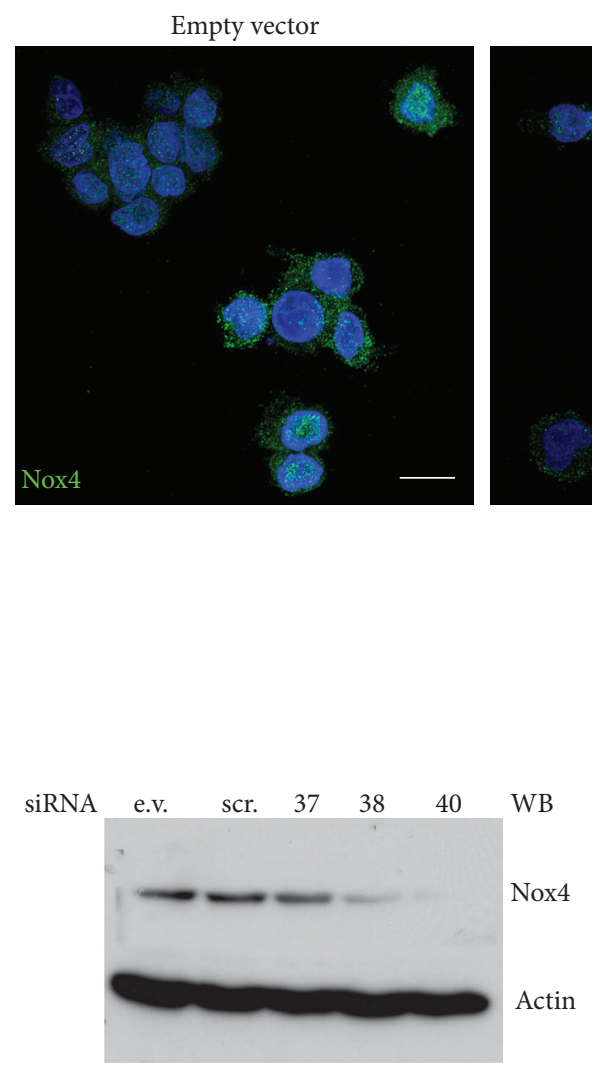

(d)

(c)

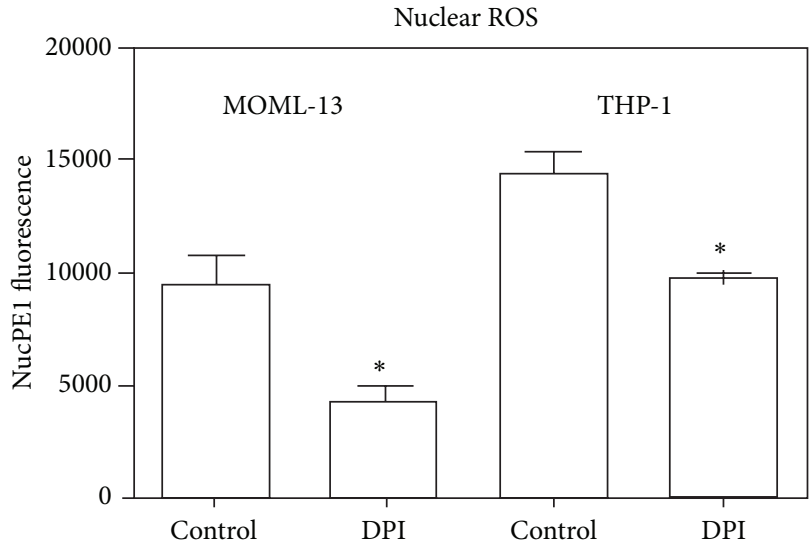

(b)
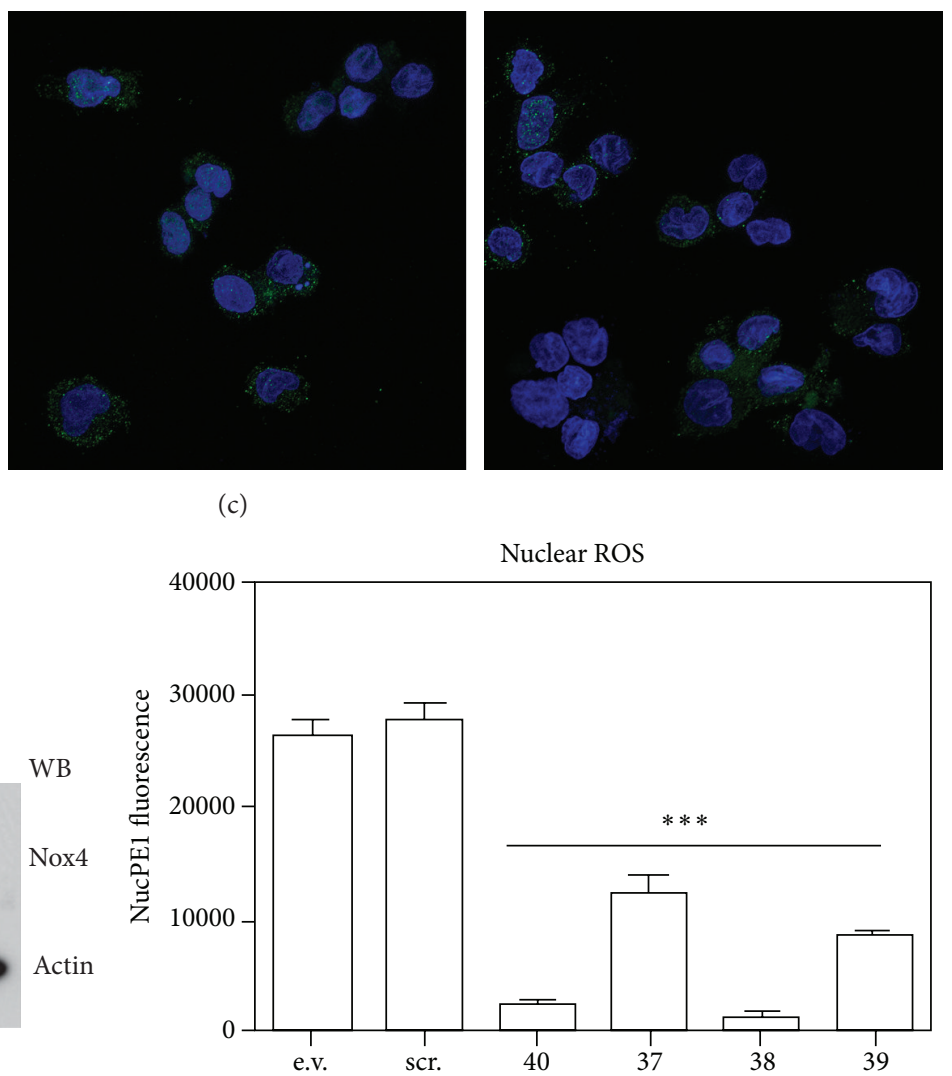

(e)

FIGURE 4: Effect of Nox4 inhibition on nuclear ROS production. (a) Representative images showing staining with nuclear ROS probe (nuclear peroxy Emerald 1) of THP1 in the presence or absence of $2 \mu \mathrm{M}$ DPI for 18 hours. Scale bar: $10 \mu \mathrm{m}$. (b) Graph representing fluorescence intensity of nuclear ROS probe (Nuclear peroxy Emerald 1) of MOLM-13 and THP1 in the presence or absence of $2 \mu \mathrm{M}$ DPI for 18 hours. (c) Representative images showing: superimposing between DAPI (blue) and Nox4 SC (green) signals of THP1 treated with empty vector (EV) or Nox4-directed siRNA (38 and 40) as reported in Section 2. Scale bar: $10 \mu \mathrm{m}$. (d) Representative images of Western blot analysis of Nox4 silencing in THP1 cells. $\beta$ actin was used as loading internal control. (e) Graph representing fluorescence intensity of nuclear ROS probe (Nuclear peroxy Emerald 1) of THP1 treated with empty vector (EV), scrambled siRNA (SCR), or Nox4-directed siRNA (37, 38, 39, and 40). Presented data are representative of three independent experiments. ${ }^{*} P<0.05$ and ${ }^{* * *} P<0.001$ versus Control. 


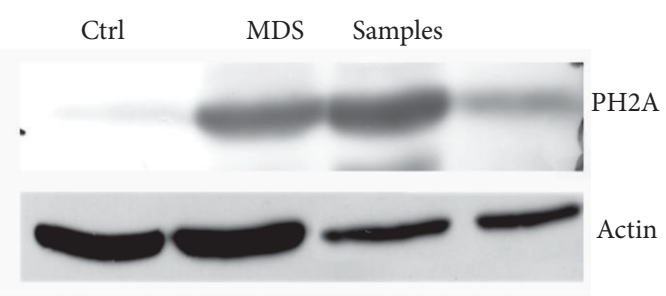

(a)

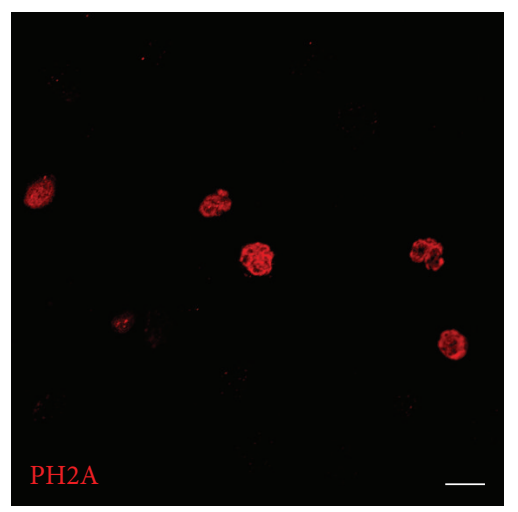

Human MDS samples
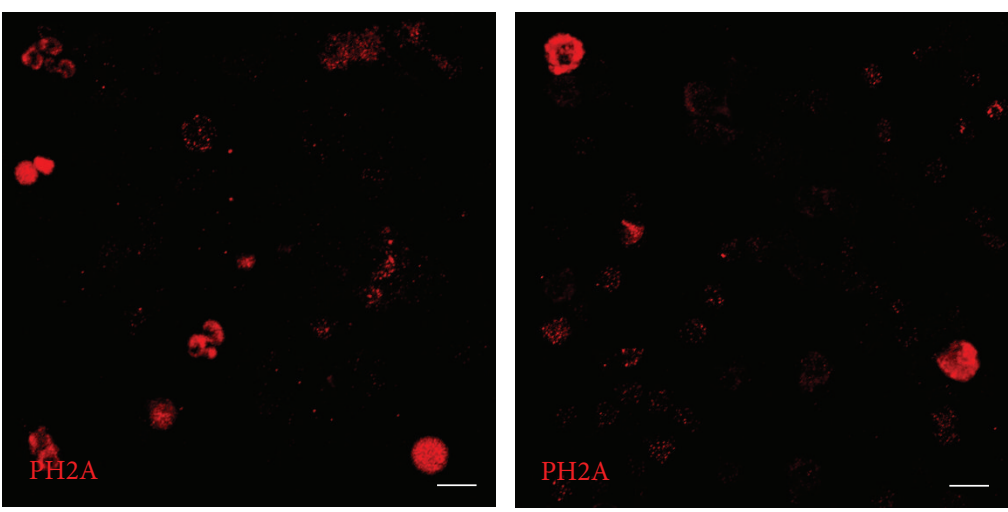

(b)

FIGURE 5: DNA damage in MDS samples. (a) Representative images showing staining with anti-PH2A (red), as marker of DNA damage, in three human MDS samples. Scale bar: $10 \mu \mathrm{m}$. (b) Western blot analysis of total lysates of MDS samples revealed with anti-PH2A. $\beta$ actin was used as loading internal control.

modulation of nuclear signaling and DNA damage. For example, Nox 4 can be a critical mediator in oncogenic RASinduced DNA-damage response.

In addition to antioxidant therapy, targeted therapy for STAT, RAS, and PI3K pathways, such as RAC1 [16], may be amenable to inhibition of nuclear ROS sources and genomic instability using small molecule inhibitors.

These therapeutic options are likely to represent important treatments in MDS/AML. Nevertheless, efficacy of ROS reduction on the reversal of genomic instability and disease progression may rely on elucidation of the major routes for ROS overproduction in cancer with multiple genetic alterations.
Abbreviations
AML: acute myeloid leukemia
BM: bone marrow
BSA: bovine serum albumin
DABCO: 1,4-diazabicyclo(2.2.2)octane
DAPI: $\quad 4^{\prime}, 6$-diamidino-2-phenylindole
DPI: diphenyleneiodonium
EDTA: ethylenediaminetetraacetic acid
PBMCs: peripheral blood samples
PBS: $\quad$ phosphate buffered saline
MDSs: myelodysplastic syndromes

Nox: NADPH oxidase

nNox4: nuclear NOX4

RA: refractory anemia

PI3K: phosphatidylinositol 3 kinase

RARS: RA with ringed sideroblasts

RAEB: RA with excess of blasts

RCMD: refractory cytopenia with multilineage dysplasia

ROS: reactive oxygen species

TBS: Tris-buffered saline

Tx: Triton-X-100.

\section{Conflict of Interests}

The authors declare that there is no conflict of interests regarding the publication of this paper.

\section{Authors' Contribution}

Marianna Guida and Tullia Maraldi equally contributed to this work.

\section{Acknowledgments}

The authors thank Dr. Christopher J. Chang and Dr. Bryan C. Dickinson, Department of Chemistry, University of California, Berkeley, CA, USA, for gently providing Nuclear 

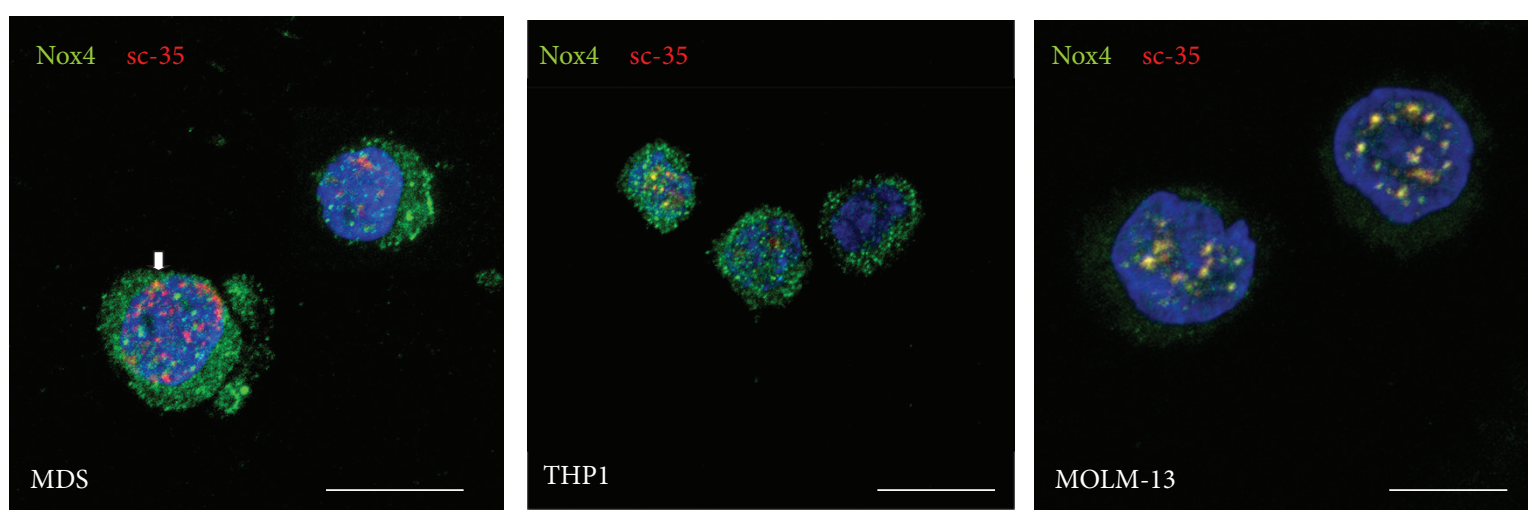

(a)

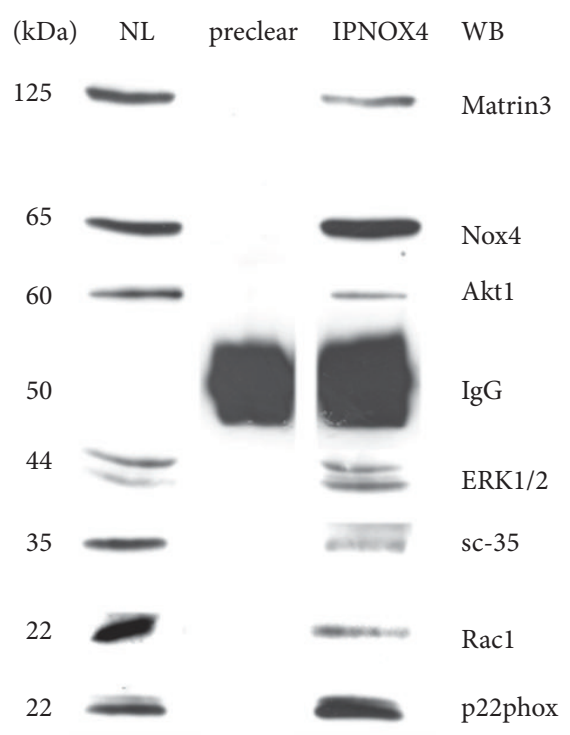

(b)

Figure 6: Nox4 nuclear interaction. (a) Representative images showing superimposing between DAPI (blue), Nox4 (green), and sc-35 (red) signals in MDS, MOLM-13, and THP1 cells. Scale bar: $10 \mu \mathrm{m}$. (b) Representative images of Western blot analysis of nuclear lysate (NL), preclearing (preclear) sample obtained, as described in methods section, before immunoprecipitation experiment with Nox 4 antibody (IPNOX4): these samples were then revealed with anti-Matrin3, anti-Nox4, anti-Akt1, anti-ERK1/2, anti-sc-35, anti-Racl, and anti-p22phox. All presented data are representative of three independent experiments.

peroxy Emerald 1. This work was supported by grants from MIUR PRIN 2009 Prot: 200938XJLA_002. The authors thank Professor Lucio I. Cocco for the project design.

\section{References}

[1] F. V. Rassool, T. J. Gaymes, N. Omidvar et al., "Reactive oxygen species, DNA damage, and error-prone repair: a model for genomic instability with progression in myeloid leukemia?" Cancer Research, vol. 67, no. 18, pp. 8762-8771, 2007.

[2] W. Guo, Z. Keckesova, J. L. Donaher et al., "Slug and Sox9 cooperatively determine the mammary stem cell state," Cell, vol. 148, no. 5, pp. 1015-1028, 2012.

[3] A. Mijović and G. J. Mufti, "The myelodysplastic syndromes: towards a functional classification," Blood Reviews, vol. 12, no. 2, pp. 73-83, 1998.
[4] A. S. Watson, M. Mortensen, and A. K. Simon, "Autophagy in the pathogenesis of myelodysplastic syndrome and acute myeloid leukemia," Cell Cycle, vol. 10, no. 11, pp. 1719-1725, 2011.

[5] S. D. Nimer, "Myelodysplastic syndromes," Blood, vol. 111, no. 10, pp. 4841-4851, 2008.

[6] P. Greenberg, C. Cox, M. M. LeBeau et al., "International scoring system for evaluating prognosis in myelodysplastic syndromes," Blood, vol. 89, no. 6, pp. 2079-2088, 1997.

[7] O. A. Sedelnikova, C. E. Redon, J. S. Dickey, A. J. Nakamura, A. G. Georgakilas, and W. M. Bonner, "Role of oxidatively induced DNA lesions in human pathogenesis," Mutation Research, vol. 704, no. 1-3, pp. 152-159, 2010.

[8] G. Slupphaug, B. Kavli, and H. E. Krokan, "The interacting pathways for prevention and repair of oxidative DNA damage," Mutation Research, vol. 531, no. 1-2, pp. 231-251, 2003.

[9] F. Steinboeck, M. Hubmann, A. Bogusch, P. Dorninger, T. Lengheimer, and E. Heidenreich, "The relevance of oxidative stress and cytotoxic DNA lesions for spontaneous mutagenesis 
in non-replicating yeast cells," Mutation Research, vol. 688, no. 1-2, pp. 47-52, 2010.

[10] M. Themeli, L. Petrikkos, M. Waterhouse et al., "Alloreactive microenvironment after human hematopoietic cell transplantation induces genomic alterations in epithelium through an ROS-mediated mechanism: in vivo and in vitro study and implications to secondary neoplasia," Leukemia, vol. 24, no. 3, pp. 536-543, 2010.

[11] A. Sallmyr, J. Fan, K. Datta et al., "Internal tandem duplication of FLT3 (FLT3/ITD) induces increased ROS production, DNA damage, and misrepair: implications for poor prognosis in AML," Blood, vol. 111, no. 6, pp. 3173-3182, 2008.

[12] M. J. Farquhar and D. T. Bowen, "Oxidative stress and the myelodysplastic syndromes," International Journal of Hematology, vol. 77, no. 4, pp. 342-350, 2003.

[13] H. Ghoti, J. Amer, A. Winder, E. Rachmilewitz, and E. Fibach, "Oxidative stress in red blood cells, platelets and polymorphonuclear leukocytes from patients with myelodysplastic syndrome," European Journal of Haematology, vol. 79, no. 6, pp. 463-467, 2007.

[14] B. Novotna, Y. Bagryantseva, M. Siskova, and R. Neuwirtova, "Oxidative DNA damage in bone marrow cells of patients with low-risk myelodysplastic syndrome," Leukemia Research, vol. 33, no. 2, pp. 340-343, 2009.

[15] C. M. Peddie, C. R. Wolf, L. I. Mclellan, A. R. Collins, and D. T. Bowen, "Oxidative DNA damage in $\mathrm{CD} 34^{+}$myelodysplastic cells is associated with intracellular redox changes and elevated plasma tumour necrosis factor- $\alpha$ concentration," British Journal of Haematology, vol. 99, no. 3, pp. 625-631, 1997.

[16] A. Sallmyr, J. Fan, and F. V. Rassool, "Genomic instability in myeloid malignancies: increased reactive oxygen species (ROS), DNA double strand breaks (DSBs) and error-prone repair," Cancer Letters, vol. 270, no. 1, pp. 1-9, 2008.

[17] Q. Xu, S.-E. Simpson, T. J. Scialla, A. Bagg, and M. Carroll, "Survival of acute myeloid leukemia cells requires PI3 kinase activation," Blood, vol. 102, no. 3, pp. 972-980, 2003.

[18] C. Prata, T. Maraldi, D. Fiorentini, L. Zambonin, G. Hakim, and L. Landi, "Nox-generated ROS modulate glucose uptake in a leukaemic cell line," Free Radical Research, vol. 42, no. 5, pp. 405-414, 2008.

[19] T. Maraldi, C. Prata, F. Vieceli Dalla Sega et al., "NAD(P)H oxidase isoform Nox2 plays a prosurvival role in human leukaemia cells," Free Radical Research, vol. 43, no. 11, pp. 11111121, 2009.

[20] T. Maraldi, C. Prata, C. Caliceti et al., "VEGF-induced ROS generation from $\mathrm{NAD}(\mathrm{P}) \mathrm{H}$ oxidases protects human leukemic cells from apoptosis," International Journal of Oncology, vol. 36, no. 6, pp. 1581-1589, 2010.

[21] T. Finkel, "Intracellular redox regulation by the family of small GTPases," Antioxidants and Redox Signaling, vol. 8, no. 9-10, pp. 1857-1863, 2006.

[22] M. Ushio-Fukai, "Compartmentalization of redox signaling through NaDPH oxidase-derived rOS," Antioxidants and Redox Signaling, vol. 11, no. 6, pp. 1289-1299, 2009.

[23] T. Kietzmann, "Intracellular redox compartments: mechanisms and significances," Antioxidants and Redox Signaling, vol. 13, no. 4, pp. 395-398, 2010.

[24] J. Kuroda, K. Nakagawa, T. Yamasaki et al., "The superoxideproducing $\mathrm{NAD}(\mathrm{P}) \mathrm{H}$ oxidase Nox4 in the nucleus of human vascular endothelial cells," Genes to Cells, vol. 10, no. 12, pp. 11391151, 2005.
[25] M. Lukosz, S. Jakob, N. Büchner, T.-C. Zschauer, J. Altschmied, and J. Haendeler, "Nuclear redox signaling," Antioxidants and Redox Signaling, vol. 12, no. 6, pp. 713-742, 2010.

[26] J. W. Vardiman, N. L. Harris, and R. D. Brunning, "The World Health Organization (WHO) classification of the myeloid neoplasms," Blood, vol. 100, no. 7, pp. 2292-2302, 2002.

[27] Y. Matsuo, R. A. F. MacLeod, C. C. Uphoff et al., "Two acute monocytic leukemia (AML-M5a) cell lines (MOLM-13 and MOLM-14) with interclonal phenotypic heterogeneity showing MLL-AF9 fusion resulting from an occult chromosome insertion, ins(11;9)(q23;p22p23)," Leukemia, vol. 11, no. 9, pp. 14691477, 1997.

[28] C. Fabre, G. Carvalho, E. Tasdemir et al., "NF- $\kappa$ B inhibition sensitizes to starvation-induced cell death in high-risk myelodysplastic syndrome and acute myeloid leukemia," Oncogene, vol. 26, no. 28, pp. 4071-4083, 2007.

[29] T. Maraldi, J. Bertacchini, M. Benincasa et al., "Reverse-phase protein microarrays (RPPA) as a diagnostic and therapeutic guide in multidrug resistant leukemia," International Journal of Oncology, vol. 38, no. 2, pp. 427-435, 2011.

[30] V. Cenni, A. Bavelloni, F. Beretti et al., "Ankrd2/ARPP is a novel Akt2 specific substrate and regulates myogenic differentiation upon cellular exposure to $\mathrm{H}_{2} \mathrm{O}_{2}$," Molecular Biology of the Cell, vol. 22, no. 16, pp. 2946-2956, 2011.

[31] J. Bertacchini, F. Beretti, V. Cenni et al., "The protein kinase Akt/PKB regulates both prelamin A degradation and Lmna gene expression," The FASEB Journal, vol. 27, no. 6, pp. 21452155, 2013.

[32] C. J. Hanson, M. D. Bootman, C. W. Distelhorst, T. Maraldi, and H. L. Roderick, "The cellular concentration of Bcl-2 determines its pro- or anti-apoptotic effect," Cell Calcium, vol. 44, no. 3, pp. 243-258, 2008.

[33] E. Resca, M. Zavatti, L. Bertoni et al., "Enrichment in c-Kit+ enhances mesodermal and neural differentiation of human chorionic placental cells," Placenta, vol. 34, no. 7, pp. 526-535, 2013.

[34] A. Pisciotta, M. Riccio, G. Carnevale et al., "Human serum promotes osteogenic differentiation of human dental pulp stem cells in vitro and in vivo," PLOS ONE, vol. 7, no. 11, Article ID e50542, 2012.

[35] M. Riccio, E. Resca, T. Maraldi et al., "Human dental pulp stem cells produce mineralized matrix in 2D and 3D cultures," European Journal of Histochemistry, vol. 54, no. 4, article e46, 2010.

[36] B. C. Dickinson, Y. Tang, Z. Chang, and C. J. Chang, "A nuclearlocalized fluorescent hydrogen peroxide probe for monitoring sirtuin-mediated oxidative stress responses in vivo," Chemistry and Biology, vol. 18, no. 8, pp. 943-948, 2011.

[37] A. R. Lippert, G. C. Van De Bittner, and C. J. Chang, "Boronate oxidation as a bioorthogonal reaction approach for studying the chemistry of hydrogen peroxide in living systems," Accounts of Chemical Research, vol. 44, no. 9, pp. 793-804, 2011.

[38] V. S. Lin, B. C. Dickinson, and C. J. Chang, "Boronatebased fluorescent probes: imaging hydrogen peroxide in living systems," Methods in Enzymology, vol. 526, pp. 19-43, 2013.

[39] B. C. Dickinson and C. J. Chang, "Chemistry and biology of reactive oxygen species in signaling or stress responses," Nature Chemical Biology, vol. 7, no. 8, pp. 504-511, 2011.

[40] J. L. Kissil, M. J. Walmsley, L. Hanlon et al., "Requirement for Racl in a K-ras-induced lung cancer in the mouse," Cancer Research, vol. 67, no. 17, pp. 8089-8094, 2007. 
[41] P. Ranjan, V. Anathy, P. M. Burch, K. Weirather, J. D. Lambeth, and N. H. Heintz, "Redox-dependent expression of cyclin D1 and cell proliferation by Noxl in mouse lung epithelial cells," Antioxidants and Redox Signaling, vol. 8, no. 9-10, pp. 1447-1460, 2006.

[42] P. J. Cook, B. G. Ju, F. Telese, X. Wang, C. K. Glass, and M. G. Rosenfeld, "Tyrosine dephosphorylation of H2AX modulates apoptosis and survival decisions," Nature, vol. 458, no. 7238, pp. 591-596, 2009.

[43] M. L. Heaney and D. W. Golde, "Myelodysplasia," The New England Journal of Medicine, vol. 340, no. 21, pp. 1649-1660, 1999.

[44] S. J. Corey, M. D. Minden, D. L. Barber, H. Kantarjian, J. C. Y. Wang, and A. D. Schimmer, "Myelodysplastic syndromes: the complexity of stem-cell diseases," Nature Reviews Cancer, vol. 7, no. 2, pp. 118-129, 2007.

[45] M. J. Walter, D. Shen, L. Ding et al., "Clonal Architecture of Secondary Acute Myeloid Leukemia," The New England Journal of Medicine, vol. 366, no. 12, pp. 1090-1098, 2012.

[46] D. G. Gilliland and M. S. Tallman, "Focus on acute leukemias," Cancer Cell, vol. 1, no. 5, pp. 417-420, 2002.

[47] N. Mori, R. Morosetti, E. Hoflehner, M. Lübbert, H. Mizoguchi, and H. P. Koeffler, "Allelic loss in the progression of myelodysplastic syndrome," Cancer Research, vol. 60, no. 11, pp. 3039$3042,2000$.

[48] N. Mori, R. Morosetti, H. Mizoguchi, and H. P. Koeffler, "Progression of myelodysplastic syndrome: allelic loss on chromosomal arm 1p," British Journal of Haematology, vol. 122, no. 2, pp. 226-230, 2003.

[49] R. A. Padua, B.-A. Guinn, A. I. Al-Sabah et al., "RAS, FMS and p53 mutations and poor clinical outcome in myelodysplasias: a 10-year follow-up," Leukemia, vol. 12, no. 6, pp. 887-892, 1998.

[50] P. Fenaux, "Chromosome and molecular abnormalities in myelodysplastic syndromes," International Journal of Hematology, vol. 73, no. 4, pp. 429-437, 2001.

[51] X. Deng, F. Gao, and W. S. May Jr., "Bcl2 retards G1/S cell cycle transition by regulating intracellular ROS," Blood, vol. 102, no. 9, pp. 3179-3185, 2003.

[52] K. D. Mills, D. O. Ferguson, and F. W. Alt, "The role of DNA breaks in genomic instability and tumorigenesis," Immunological Reviews, vol. 194, pp. 77-95, 2003.

[53] M. Kochetkova, P. O. Iversen, A. F. Lopez, and M. F. Shannon, "Deoxyribonucleic acid triplex formation inhibits granulocyte macrophage colony-stimulating factor gene expression and suppresses growth in juvenile myelomonocytic leukemic cells," Journal of Clinical Investigation, vol. 99, no. 12, pp. 3000-3008, 1997.

[54] R. Serù, P. Mondola, S. Damiano et al., "HaRas activates the $\mathrm{NADPH}$ oxidase complex in human neuroblastoma cells via extracellular signal-regulated kinase 1/2 pathway," Journal of Neurochemistry, vol. 91, no. 3, pp. 613-622, 2004.

[55] A. M. Martelli, L. Cocco, S. Capitani, S. Miscia, S. Papa, and F. A. Manzoli, "Nuclear phosphatidylinositol 3,4,5-trisphosphate, phosphatidylinositol 3-kinase, Akt, and PTen: emerging key regulators of anti-apoptotic signaling and carcinogenesis," European Journal of Histochemistry, vol. 51, pp. 125-131, 2007.

[56] M. J. Zeitz, K. S. Malyavantham, B. Seifert, and R. Berezney, "Matrin 3: chromosomal distribution and protein interactions," Journal of Cellular Biochemistry, vol. 108, no. 1, pp. 125-133, 2009. 

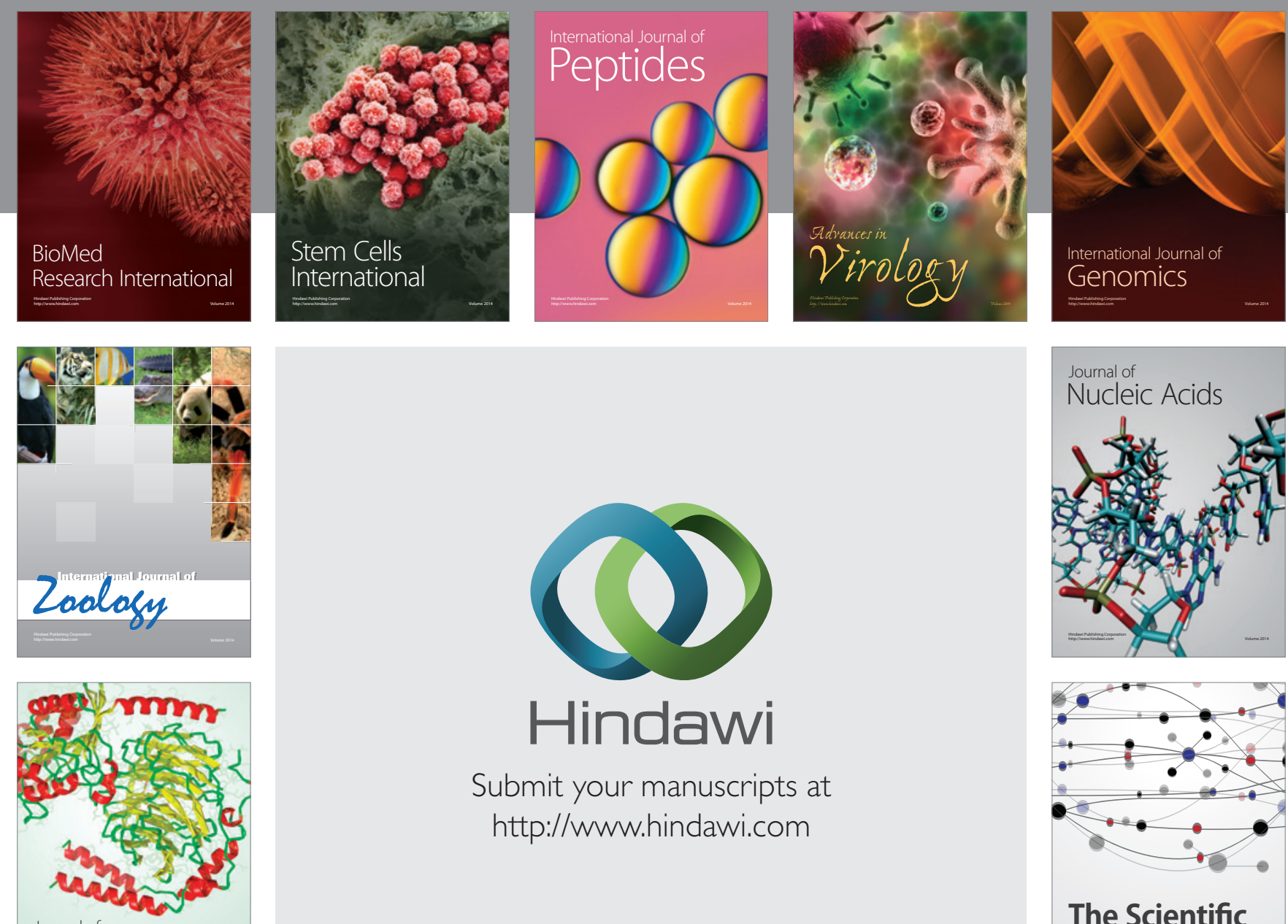

Submit your manuscripts at

http://www.hindawi.com

Journal of
Signal Transduction
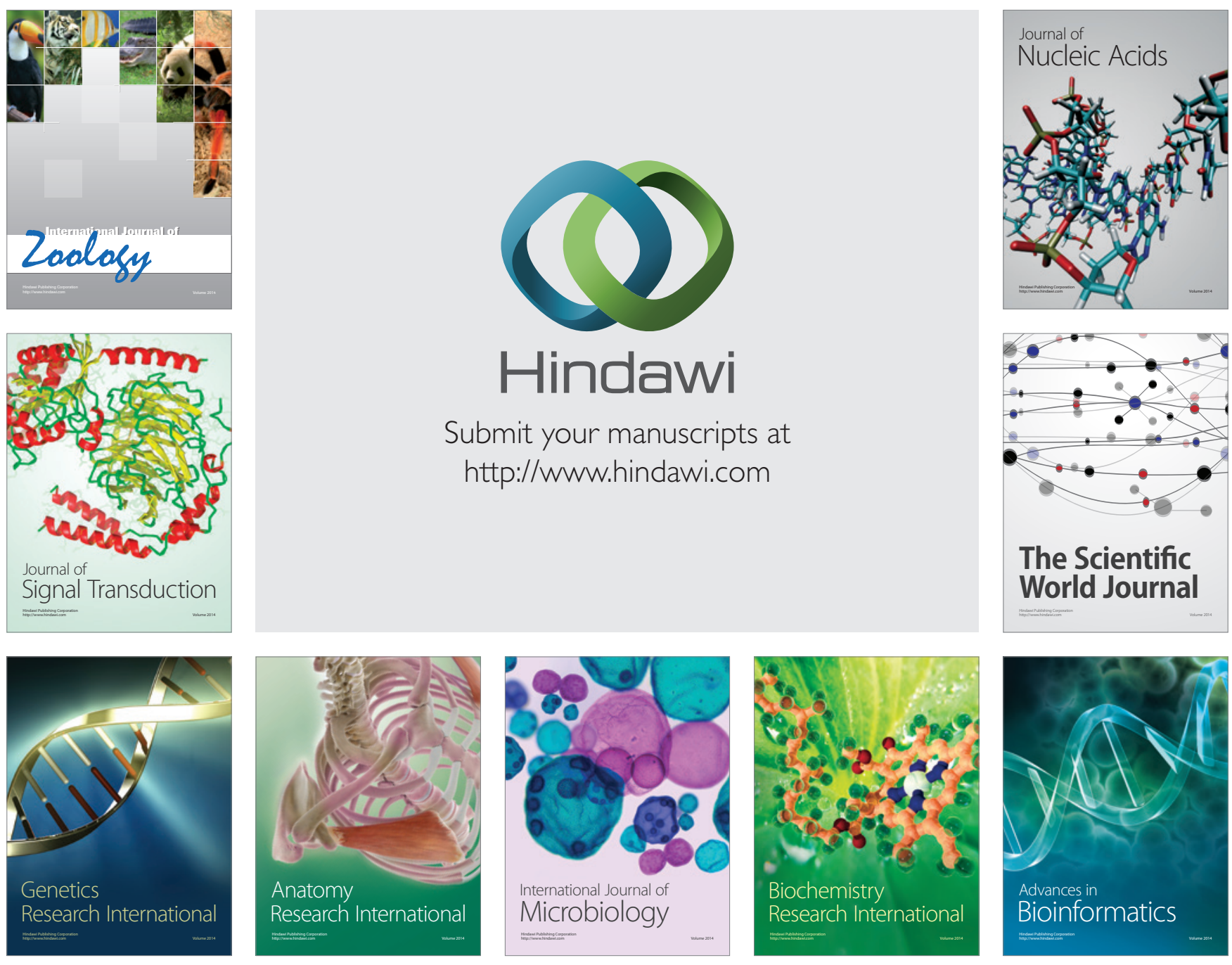

The Scientific World Journal
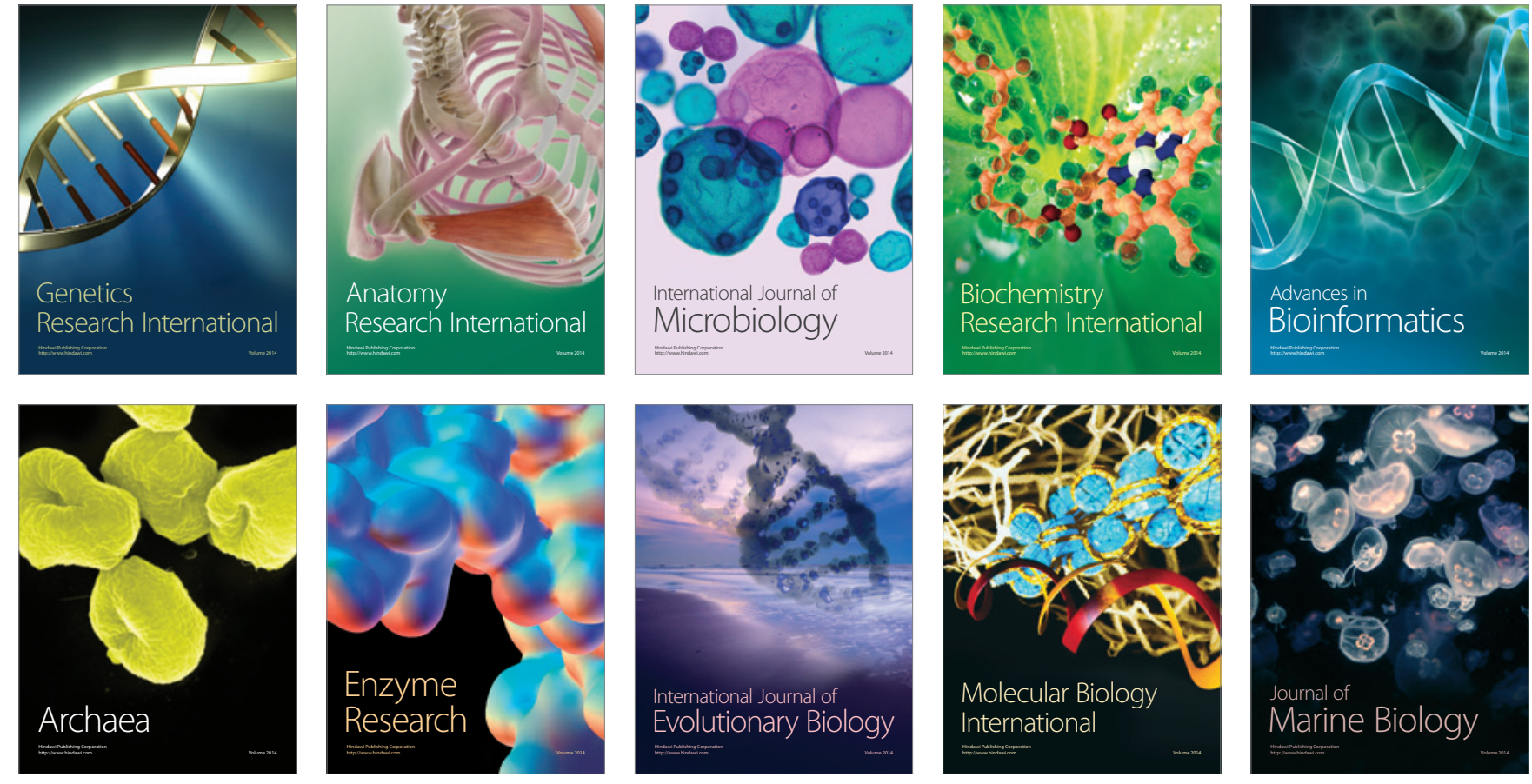